Research Article

\title{
Multiaxis Servo Synergic Control Based on Sliding Mode Controller
}

\author{
Jing He $\mathbb{D}^{\mathbb{D}}$, Xiang Jiang $(\mathbb{D}$, Changfan Zhang $(\mathbb{D}$, Jin Ding $\mathbb{B}$, Zhitian Liu $(\mathbb{D}$, \\ Xueyuan Chen $\mathbb{D}$, and Buchong Yang $\mathbb{D}$ \\ College of Electrical and Information Engineering, Hunan University of Technology, Zhuzhou 412000, China \\ Correspondence should be addressed to Changfan Zhang; zhangchangfan@263.net
}

Received 25 April 2019; Revised 30 July 2019; Accepted 6 September 2019; Published 1 October 2019

Academic Editor: Javad M. Velni

Copyright ( $\odot 2019$ Jing He et al. This is an open access article distributed under the Creative Commons Attribution License, which permits unrestricted use, distribution, and reproduction in any medium, provided the original work is properly cited.

\begin{abstract}
This paper investigates a relative coupling control strategy based on the sliding mode controller to solve the problem of poor synergy performance of the axes of the dynamic seat during operation and to realize the multiaxis servo synergic control with variable proportions during the operation of the system. Firstly, the proposed method is theoretically proven to be accurate in eliminating tracking errors and synchronization errors between servos in the process of system operation. Secondly, the system simulation model is built in the Simulink simulation environment of MATLAB. On one hand, the final simulation result verifies the accuracy of the theoretical proof. On the other hand, the control strategy is characterized by fast convergence, high synchronization accuracy, and strong robustness; thus, the system has excellent synergy performance. Finally, the motion control platform of the dynamic seat was built for physical verification. The experimental result shows the effectiveness and feasibility of the control strategy.
\end{abstract}

\section{Introduction}

Multiaxis servo synergic control technology has been widely used in the field of industrial control. Synchronization control is the key problem to be studied [1]. At present, multiaxis servo synergic control structure $[2,3]$ mainly includes master-slave type, virtual line-shaft type, cross-coupling type, relative coupling type, and ring coupling type. From the existing study results, the masterslave type is proposed in [4], whereas the virtual line-shaft type is adopted in [5]. Although these control structures are simple in design and easy to implement, the synchronization control performance is poor due to the failure of introducing signal feedback mechanism. For further improvement, the cross-coupling control structure is adopted in [6]. However, it can only be applied to two motors as pointed out in [7]. Thus, it cannot be effectively promoted. Therefore, the relative coupling control structure was proposed in [8]. The relative coupling structure is used to research the multiservo system with three or more servos in [9-11], and the results show that this structure has good synchronization performance. However, with the deepening of research, the limitation was pointed out in [12] that the complexity of the system structure would increase with the increase of the number of motors when the deviation coupling control structure was adopted. The ring coupling control structure proposed in [13] and the adjacent cross-coupling control structure adopted in [14] ensure the synchronous control effect and reduce the complexity of multiaxis servo control. However, it only considers the motion state of the adjacent servo, which will lead to the nonuniform response of all motors [15] due to the conduction delay from velocity variation [16].

In the control algorithm, to improve the synchronization accuracy of multiaxis servo control system, Shi et al. [17] 
proposed a multiaxis servo synchronization control strategy based on the combination of relative coupling control and virtual line-shaft control, which can overcome the synchronization error caused by external disturbance and parameter changes and can achieve better synchronization control of the multiaxis servo system. Li et al. [15] proposed an average relative coupling synchronization control architecture based on a second-order adaptive sliding mode control (SOASMC), which can improve the synchronization control accuracy of the multimotor control system and ensure the robustness of SMC to various uncertainties and external disturbances. Zhao and Ren [18] proposed a tracking and synchronization control method based on a neural network to solve the contradiction between overshoot and rapidity and reduce overshoot and stabilization time. Huang et al. [19] proposed a coupling multiaxis servo synergic control strategy based on the wavelet neural network to effectively improve the synchronization control accuracy of the system by using the strong learning ability and rapid convergence of the wavelet neural network and combining with the fuzzy PID algorithm. Huang et al. [20] proposed an accurate controller combined with an adjacent cross-coupling control (ACCC) strategy and an adaptive global sliding mode algorithm (AGSMC) that considers the existence of coupling dynamics characteristic between the adjacent exciters. This controller can reduce speed overshooting during the start-up phase of the induction motor and the chattering when the speed is stable, as well as improve the control accuracy. Chen et al. [21] proposed a new robust control strategy for dual-motor systems by incorporating second-order sliding mode control (2-SMC) techniques. They also designed a cross-coupled architecturebased synchronous controller, which reduces the speed error of the motors caused by the characteristic inconsistency and unbalanced load torque. Sun et al. [22] proposed a ring coupling synchronization control strategy based on the fuzzy sliding mode control algorithm. This strategy realizes the synchronous control of multiple induction motor drives at different operating conditions and enhances system stability. Li et al. [12] proposed a new control approach for speed tracking and synchronization of multiple motors by incorporating an adaptive sliding mode control (ASMC) technique into a ring coupling synchronization control structure. This approach can stabilize the speed tracking of each motor and synchronize its motion with that of other motors, thereby enabling the speed tracking and synchronization errors to converge to zero. These different algorithms and control techniques to achieve the precise synchronous control of the multimotor system, but the synchronization control of the system under the variable proportion condition is not included in these studies.

On the basis of the aforementioned research, combined with the advantages of the sliding mode variable structure control $[23,24]$, such as rapid response and insensitivity to parameter perturbations and external disturbances, a multiaxis servo relative coupling control strategy based on a sliding mode controller is proposed for the actual variable proportion conditions of the multiaxis servo system. It is used to realize the synchronization control of the axes in the multiaxis servo system under variable proportion conditions by combining the velocity compensator based on fixed gain. The main contributions of this study are as follows: Firstly, the current research presents a complete theoretical proof of the relative coupling control structure based on a sliding mode controller that can simultaneously realize servo tracking and synchronization controls amongst the servos. Hence, this proof provides a theoretical basis for further research. Secondly, the synchronization control of all servos of the multiaxis servo system under variable-proportional working conditions based on the control strategy proposed in this study significantly guides the synchronization control of a multiaxis servo system with the same conditions.

The remainder of this paper is organized as follows: The second section describes the relative coupling control strategy. In the third section, a theoretical verification is carried out whilst the synchronization controller is designed. In the fourth section, MATLAB simulation and analysis is carried out. The fifth section shows the physical verification. The sixth section shows the main conclusions of this paper.

\section{Relative Coupling Control Strategy}

Figure 1 shows a multiaxis servo synergic control structure based on the sliding mode controller investigated in this study. The figure shows that this multiaxis servo control system consists of $n$ permanent magnet synchronous servos, which can perform synchronization control among servos whilst tracking the velocity control of each servo by adopting the relative coupling control structure [25] and combining the sliding mode controller. This control system mainly consists of two parts, namely, velocity compensator [8] and sliding mode controller. The input of each servo syntheses its own velocity feedback information and the deviation information between itself and other servo velocities; thus, the error information obtained by each servo is more accurate. Finally, the system has good synergy performance.

The actual motion situation indicates that each servo shall satisfy the following relationship during the same instruction cycle $T$ as follows:

$$
\frac{\theta_{1}}{\omega_{1}}=\cdots=\frac{\theta_{i}}{\omega_{i}}=\cdots=\frac{\theta_{n}}{\omega_{n}}=T .
$$

If the velocity of the first axis $\theta_{1} / T=\omega_{1}^{*}$ is regarded as the reference velocity, based on (1), $\omega_{n}^{*}=\left(\theta_{i} / \theta_{1}\right) \omega_{1}^{*}$; then, $K_{i}=$ $\theta_{i} / \theta_{1}$ is used as the proportional relationship between the velocity of each servo and the reference velocity. The tracking error of each servo is defined as follows:

$$
e_{i}^{*}=\omega_{i}^{*}-\omega_{i}, \quad i=1,2, \ldots, n,
$$

where $\omega_{i}^{*}$ and $\omega_{i}$ refer to the reference velocity and actual output rotational speed of the $i$ th servo in the system.

In accordance with the velocity relationship among servos in the system, the synchronization error among servos is defined as follows: 


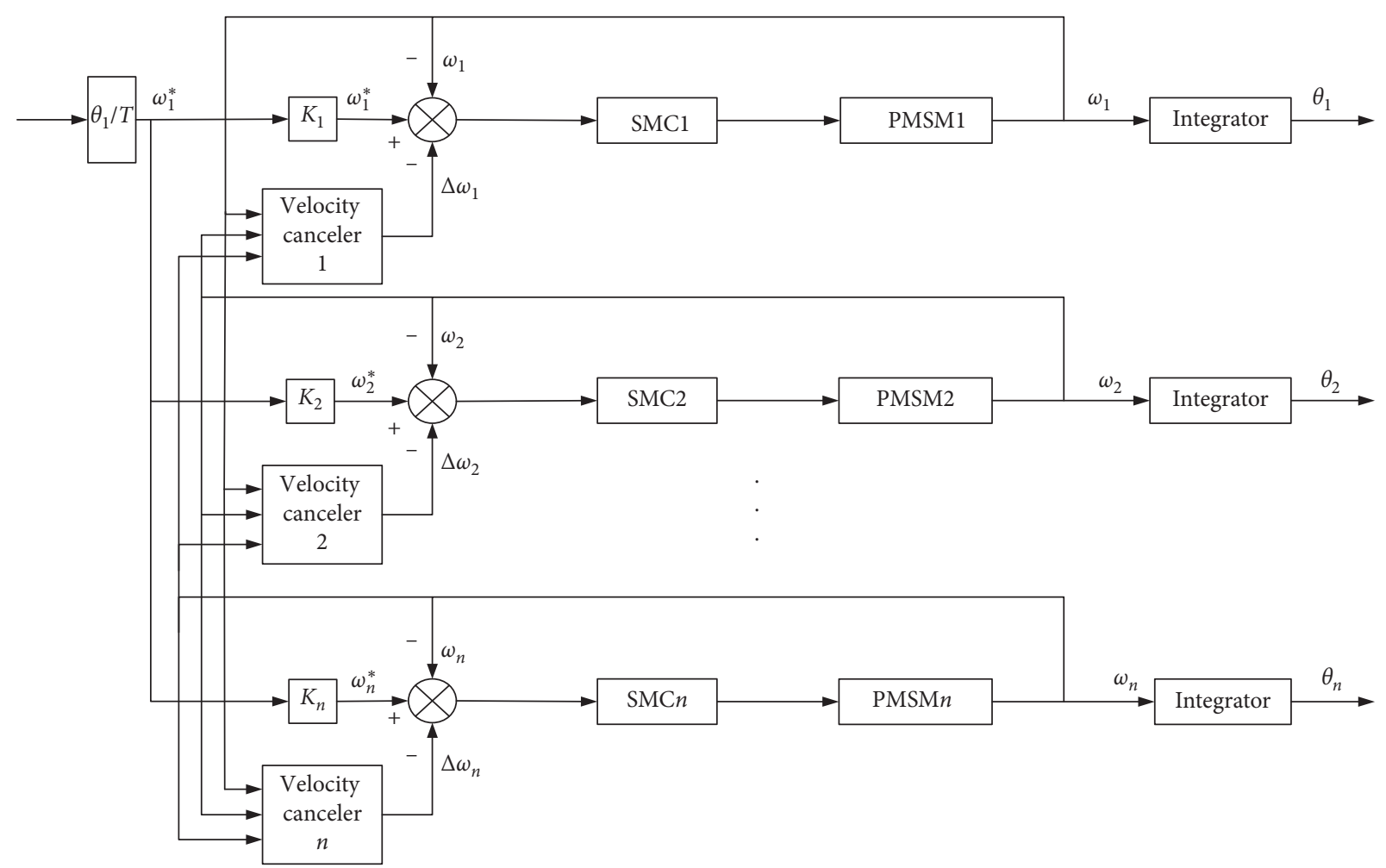

FIgURE 1: Block diagram of the sliding mode controller based on the multiaxis servo synergic control.

$$
\tau_{i j}=\frac{1}{K_{i}} \omega_{i}-\frac{1}{K_{j}} \omega_{j}, \quad i, j=1,2, \ldots, n, i \neq j,
$$

where $\tau_{i j}$ refers to the synchronization error between the $i$ th servo and the $j$ th servo in the system.

To enable the system to obtain good synchronization synergy ability, the velocity following the control of each servo, namely, $e_{i}^{*}=0$, must be ensured. Then, the synchronization operation of all servos, namely, $\tau_{i j}=0$ must also be ensured.

The actual working conditions require a rapid response of each servo. If the algorithm of the velocity compensator is extremely complex, then it causes the system to produce hysteresis phenomenon, which affects the final control effect. Therefore, a velocity compensator based on fixed gain is adopted in this study. The structure of this velocity compensator is shown in Figure 2. The fixed gain is related to the rotational inertia of each servo. Its function is to suppress the output torque jitter caused by the deviation of the rotational inertia of each servo [25]. The calculation formula is as follows:

$$
\lambda_{i j}=\frac{J_{i}}{J_{j}}, \quad i, j=1,2, \ldots, n, i \neq j,
$$

where $\lambda_{i j}$ refers to the rotational inertia ratio of the $i$ th servo and the $j$ th servo difference, i.e., fixed gain.

Figure 2 shows that, during system operation, the realtime velocity compensation signal of the $i$ th servo is $\Delta \omega_{i}$, and its value is given as follows:

$$
\Delta \omega_{i}=\sum_{j=1}^{n} \lambda_{i j}\left(\frac{1}{K_{i}} \omega_{i}-\frac{1}{K_{j}} \omega_{j}\right), \quad i, j=1,2, \ldots, n, i \neq j .
$$

\section{Design of Synchronization Controller}

This study focuses on the design of the sliding mode controller in the system and proves the accuracy of the control strategy theoretically, considering permanent magnet synchronous motor as the research object $[26,27]$.

Ideally, in the permanent magnet synchronization motor model in the $d q$ coordinate system, a coupling relationship still exists between $i_{d}$ and $i_{q} . i_{d}=0$ is adopted [28] for the control to realize the independent control of the two current components. At this time, the state equation of the $i$ th PMSM can be described as [29]

$$
\left\{\begin{array}{l}
\frac{d \theta_{i}}{d t}=\omega_{i}, \\
\frac{d \omega_{i}}{d t}=\frac{3}{2} \frac{n_{p i}^{2}}{J_{i}} \psi_{f i} i_{q i}-\frac{n_{p i}}{J_{i}} T_{L i} .
\end{array}\right.
$$

From (6), $d \omega_{i} / d t=(3 / 2)\left(n_{p i}^{2} / J_{i}\right) \psi_{f i} i_{q i}-\left(n_{p i} / J_{i}\right) T_{L i}$ is described as

$$
\dot{\omega}_{i}=C_{i} u_{i}+D_{i},
$$

where $C_{i}=(3 / 2)\left(n_{p i}^{2} / J_{i}\right) \psi_{f i}$ and $D_{i}=-\left(n_{p i} / J_{i}\right) T_{L i}$ and $u_{i}$ refers to the controller to be designed. 


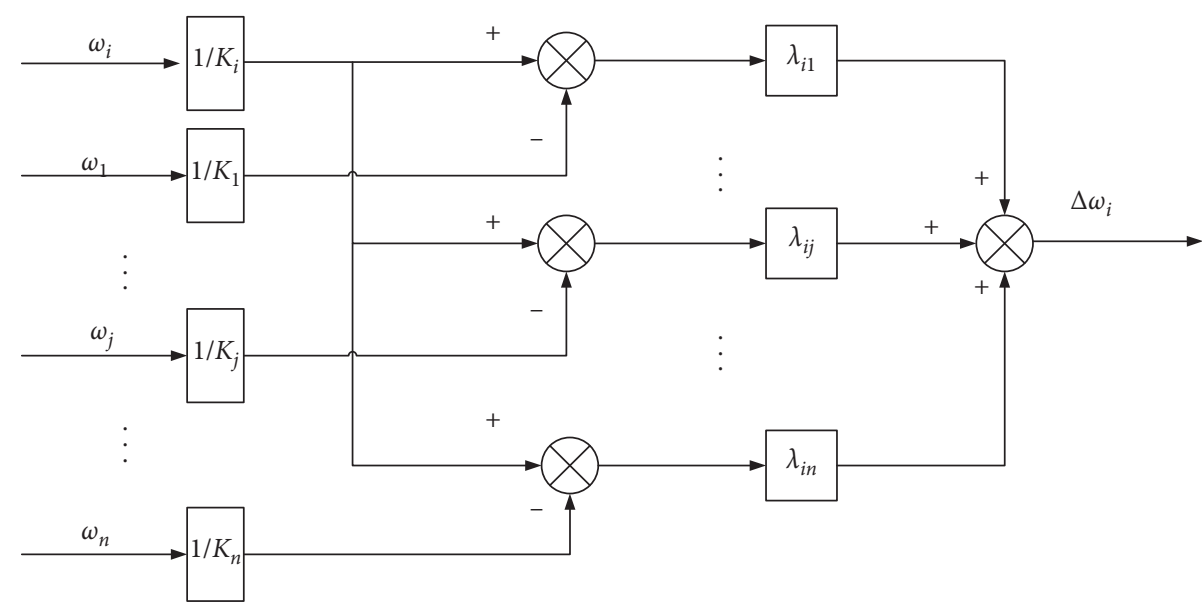

FIgURE 2: Velocity compensator structure based on fixed gain.

Combined with (2), the systematic error of the single axis after the compensation of the $i$ th servo can be obtained by the relative coupling control algorithm as follows:

$$
e_{i}=\omega_{i}^{*}-\omega_{i}-\Delta \omega_{i}=\omega_{i}^{*}-\omega_{i}-\sum_{j=1}^{n} \lambda_{i j}\left(\frac{1}{K_{i}} \omega_{i}-\frac{1}{K_{j}} \omega_{j}\right),
$$

whose derivative is given as

$$
\dot{e}_{i}=\dot{\omega}_{i}^{*}+\sum_{j=1}^{n} \frac{\lambda_{i j}}{K_{j}} \dot{\omega}_{j}-\left(1+\sum_{j=1}^{n} \frac{\lambda_{i j}}{K_{i}}\right) \dot{\omega}_{i}
$$

Design slide mode surface is given as follows:

$$
S_{i}=P_{i} e_{i}, \quad i=1,2, \ldots, n,
$$

where $P_{i}$ is a positive constant.

Taking the derivative of (10), the following is obtained by combining (7) and (9):

$$
\dot{S}_{i}=E_{i}+F_{i} u_{i}, \quad i=1,2,3
$$

where

$$
\begin{aligned}
& E_{i}=P_{i} \dot{\omega}_{i}^{*}+P_{i} \sum_{j=1}^{n} \frac{\lambda_{i j}}{K_{j}} \dot{\omega}_{j}-P_{i}\left(1+\sum_{j=1}^{n} \frac{\lambda_{i j}}{K_{i}}\right) D_{i}, \\
& F_{i}=-P_{i} C_{i}\left(1+\sum_{j=1}^{n} \frac{\lambda_{i j}}{K_{i}}\right) .
\end{aligned}
$$

In accordance with the sliding mode variable structure control theory, if $S=0$, then $S S<0$ must be satisfied to obtain the sliding mode of the system, i.e.,

$$
S_{i} \dot{S}_{i}=S_{i}\left[E_{i}+F_{i} u_{i}\right]<0 \text {. }
$$

The control rate of the sliding mode controller obtained by the exponential approach law is as follows:

$$
u_{i}=\frac{1}{F_{i}}\left[-\varepsilon_{i} \operatorname{sgn}\left(S_{i}\right)-H_{i} S_{i}-E_{i}\right], \quad i=1,2, \ldots, n,
$$

where $\operatorname{sgn}\left(S_{i}\right)$ is a sign function.
Theorem 1. The designed control rate for the multiaxis servo control system, considering the servo model described in (6) as the object, is shown in (14). When constants $H_{i}$ and $\varepsilon_{i}$ satisfy $H_{i}>0$ and $\varepsilon_{i}>0$, the control system satisfies the stability conditions for the sliding mode.

Proof. Construct the Lyapunov function as

$$
V_{i}=\frac{1}{2} S_{i}^{2}, \quad i=1,2, \ldots, n .
$$

Taking derivation of (15),

$$
\dot{V}_{i}=S_{i} \dot{S}_{i}=S_{i}\left(E_{i}+F_{i} u_{i}\right)
$$

Substituting (14) into (16) leads to the following equation:

$$
\dot{V}_{i}=-\varepsilon_{i}\left|S_{i}\right|-H_{i} S_{i}^{2}
$$

In accordance with the Lyapunov stability criterion, if $\varepsilon_{i}>0$ and $H_{i}>0$, then $\dot{V}_{i}<0$ can be guaranteed, and the convergence of the system is stable.

Therefore, if $\varepsilon_{i}>0, H_{i}>0$, and $S_{i} \dot{S}_{i}<0$, then the system satisfies the sliding mode stability condition and can reach the sliding mode surface in a limited time from any point outside the sliding mode surface [30].

The proof is thus complete.

Theorem 2. The synchronization error $\tau_{i j}$ between all servos in the system described in (3) can be converged to zero, when the systematic error $e_{i}$ after compensation satisfies $e_{i}=0$.

Proof. In Theorem $1, S_{i}=0$ refers to the system equilibrium point, then $e_{i}=0$; that is, the systematic error $e_{i}$ after compensation can be converged to zero.

From (2), (3), and (8), the following can be obtained:

$$
e_{i}=e_{i}^{*}-\left(\sum_{j=1}^{n} \frac{\lambda_{i j}}{K_{i}} \omega_{i}-\sum_{j=1}^{n} \frac{\lambda_{i j}}{K_{i}} \omega_{i}^{*}+\sum_{j=1}^{n} \frac{\lambda_{i j}}{K_{i}} \omega_{i}^{*}-\sum_{j=1}^{n} \frac{\lambda_{i j}}{K_{j}} \omega_{j}\right) .
$$


According to $\omega_{i}^{*}=k_{i} \omega_{1}^{*}$ and $\omega_{j}^{*}=k_{j} \omega_{1}^{*}$, then it follows It is expressed as a matrix, as follows: from (18) that

$$
e_{i}=\left(1+\sum_{j=1}^{n} \frac{\lambda_{i j}}{K_{i}}\right) e_{i}^{*}-\sum_{j=1}^{n} \frac{\lambda_{i j}}{K_{j}} e_{j}^{*}
$$

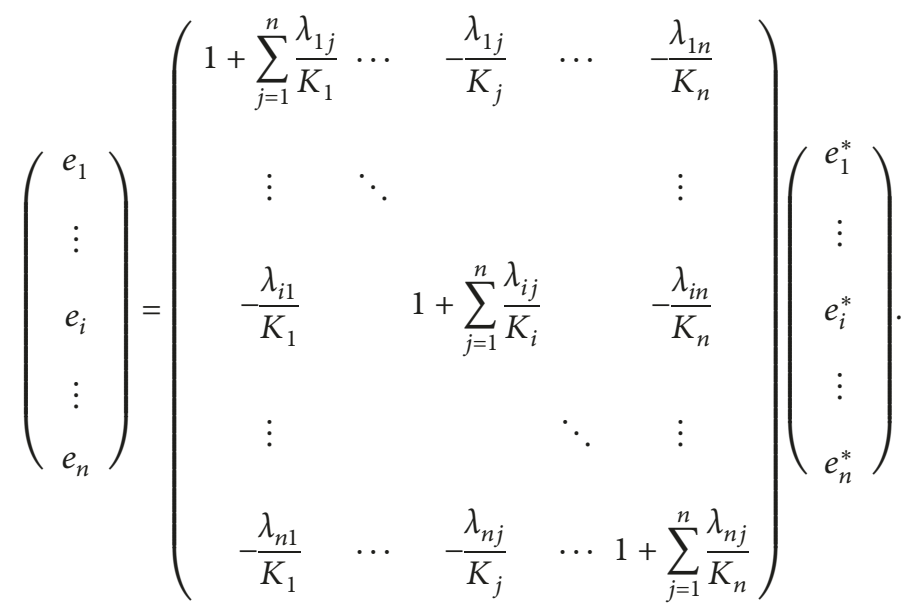

Matrix $G_{n \times n}$ is set as

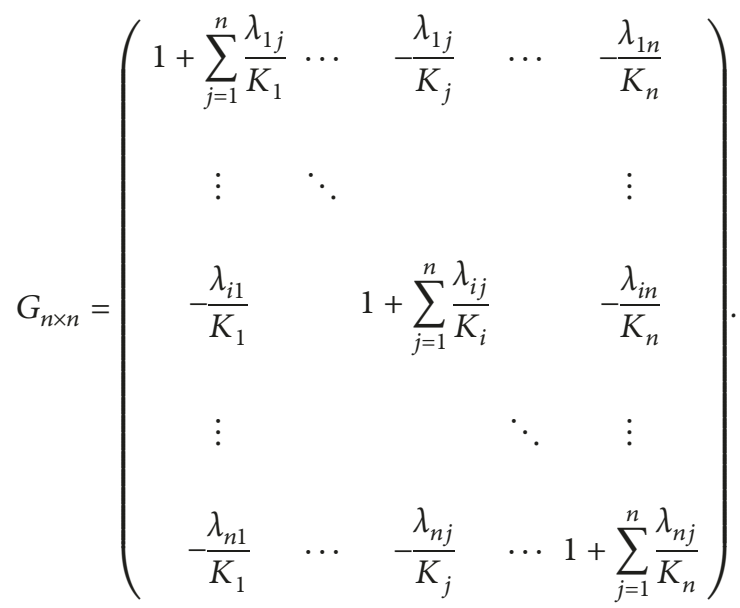

Matrix $G_{n \times n}$ becomes a full-rank square matrix after reasonably setting all parameters in $G_{n \times n}$, which is transformed into a nonsingular matrix. $e_{i}$ can be converged to zero. When it satisfies $e_{i}=0,\left[\begin{array}{ccccc}e_{1}^{*} & \cdots & e_{i}^{*} & \cdots & e_{n}^{*}\end{array}\right]^{T}$ has only a unique zero solution [30]. Thus $\omega_{i}^{*}-\omega_{i}=0$, thereby obtaining $\Delta \omega_{i}=0$, i.e.,

$$
\Delta \omega_{i}=\sum_{j=1}^{n} \lambda_{i j}\left(\frac{1}{K_{i}} \omega_{i}-\frac{1}{K_{j}} \omega_{j}\right)=0, \quad i, j=1,2, \ldots, n, i \neq j .
$$

The following is obtained combined with (4):

$$
\frac{1}{K_{i}} \omega_{i}-\frac{1}{K_{j}} \omega_{j}=0
$$

That is,

$$
\tau_{i j}=0, \quad i, j=1,2, \ldots, n, i \neq j .
$$

The proof is thus complete.

In summary, whilst designing the sliding mode controller for the system, the proposed control strategy is theoretically proven to eliminate the tracking errors and synchronization errors between the servos in the running process of the system at the same time, thereby indicating that the proposed method is correct and effective.

\section{Simulation and Result Analysis}

A three-servo relative coupling control structure system model based on the sliding mode controller is built under the Simulink environment in MATLAB to verify the accuracy and effectiveness of the proposed control strategy. At the same time, the comparative analysis on the simulation result under the traditional PI control and the adjacent crosscoupling control based on the sliding mode controller are carried out, respectively. The parameter settings of three servos are shown in Table 1.

4.1. Fixed Proportion Simulation in a Single Cycle. Considering the input velocity of the first servo as the reference velocity of the system, the velocity is set to $\omega_{1}^{*}=1500 \mathrm{r} \cdot \mathrm{min}^{-1}$. The fixed proportions are set to $k_{1}=1$, $k_{2}=0.5$, and $k_{3}=1.5$. The simulation time is set to $t=0.1 \mathrm{~s}$. The load torque of all servos is $2 \mathrm{~N} \cdot \mathrm{m}$.

Case 1. Under the circumstance that other conditions are guaranteed to be consistent, the velocity tracking curves 
TABle 1: Parameter settings of three servos.

\begin{tabular}{|c|c|c|c|c|c|c|}
\hline Servos & $n_{p}$ & Rated speed $\left(r \cdot \mathrm{min}^{-1}\right)$ & $R(\Omega)$ & $L(\mathrm{mH})$ & $\psi_{f}(\mathrm{~Wb})$ & $J\left(\mathrm{~kg} \cdot \mathrm{m}^{2}\right)$ \\
\hline 1 & 4 & 3000 & 2.775 & 8.5 & 0.185 & $8.05 \times 10^{-4}$ \\
\hline 2 & 4 & 3000 & 2.836 & 8.6 & 0.175 & $8.15 \times 10^{-4}$ \\
\hline 3 & 4 & 3000 & 2.794 & 8.4 & 0.205 & $8.25 \times 10^{-4}$ \\
\hline
\end{tabular}

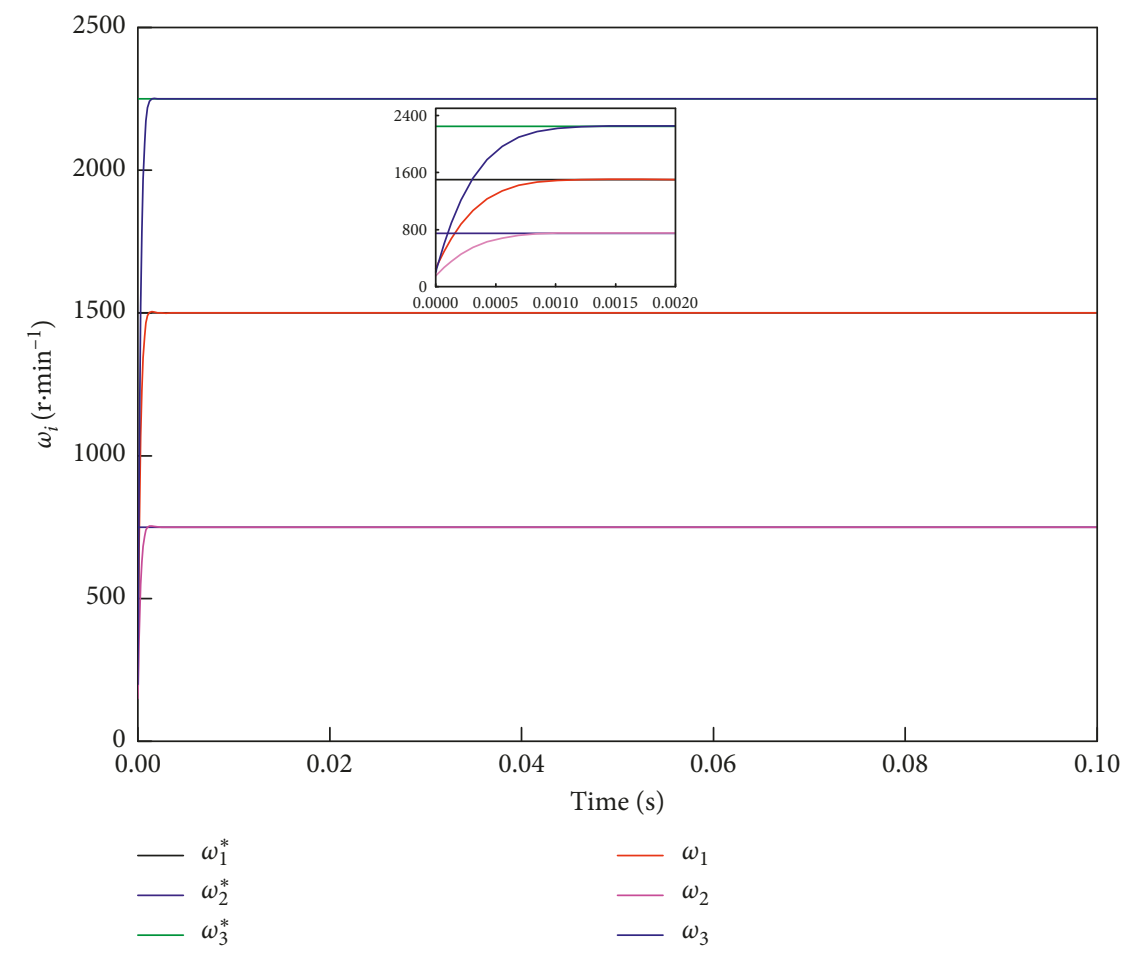

Figure 3: The velocity tracking curves of all servos under the sliding mode variable control.

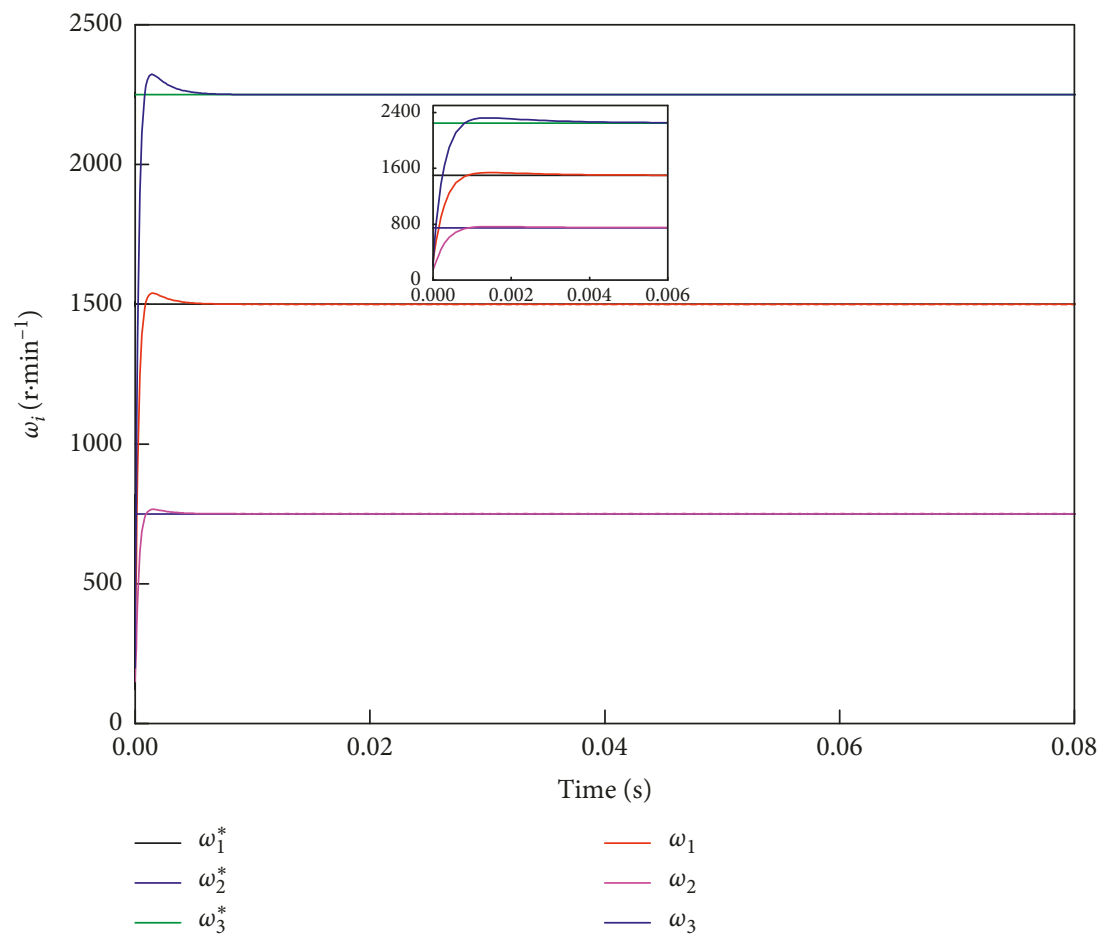

FIgURE 4: The velocity tracking curves of all servos under the traditional PI control. 


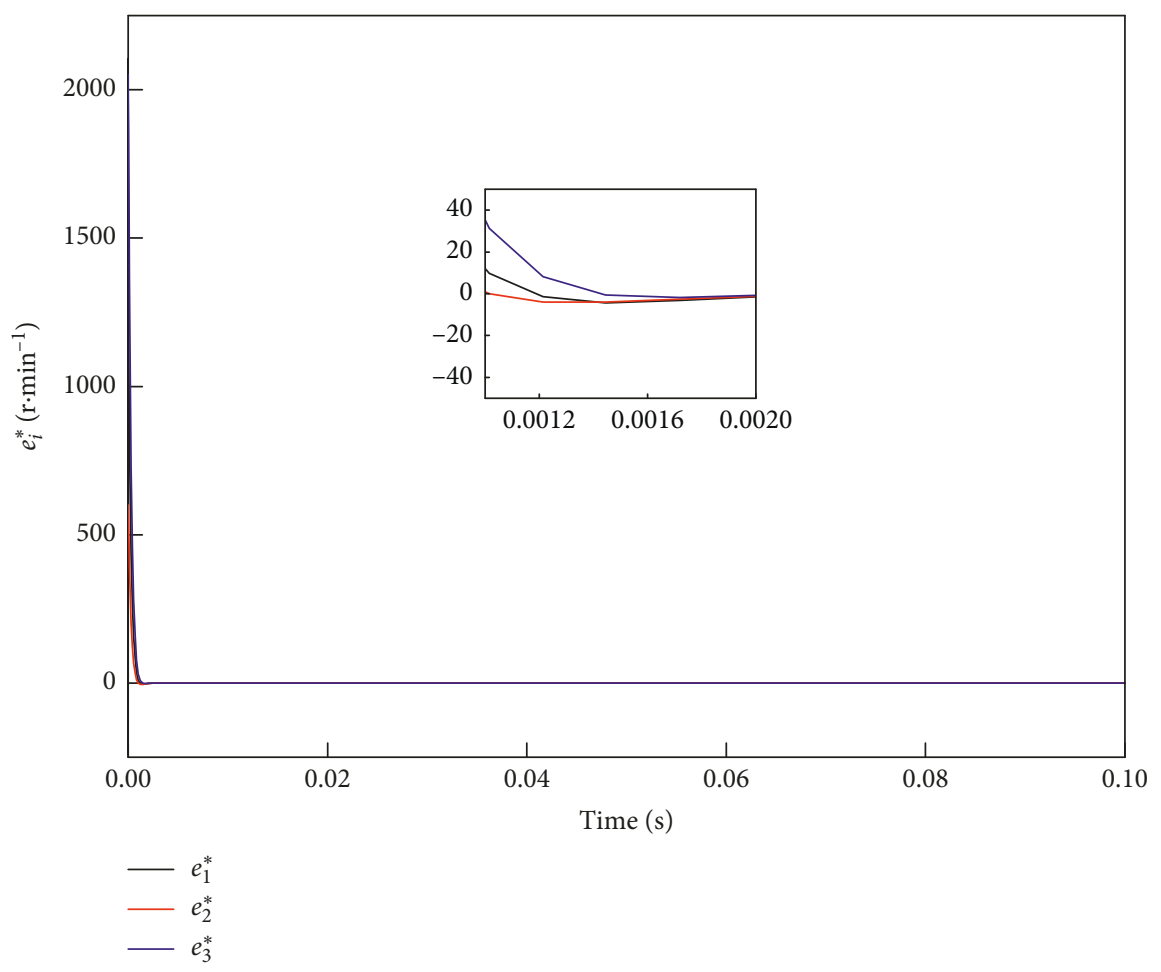

FIGURE 5: The velocity tracking error curves of all servos under the sliding mode variable control.

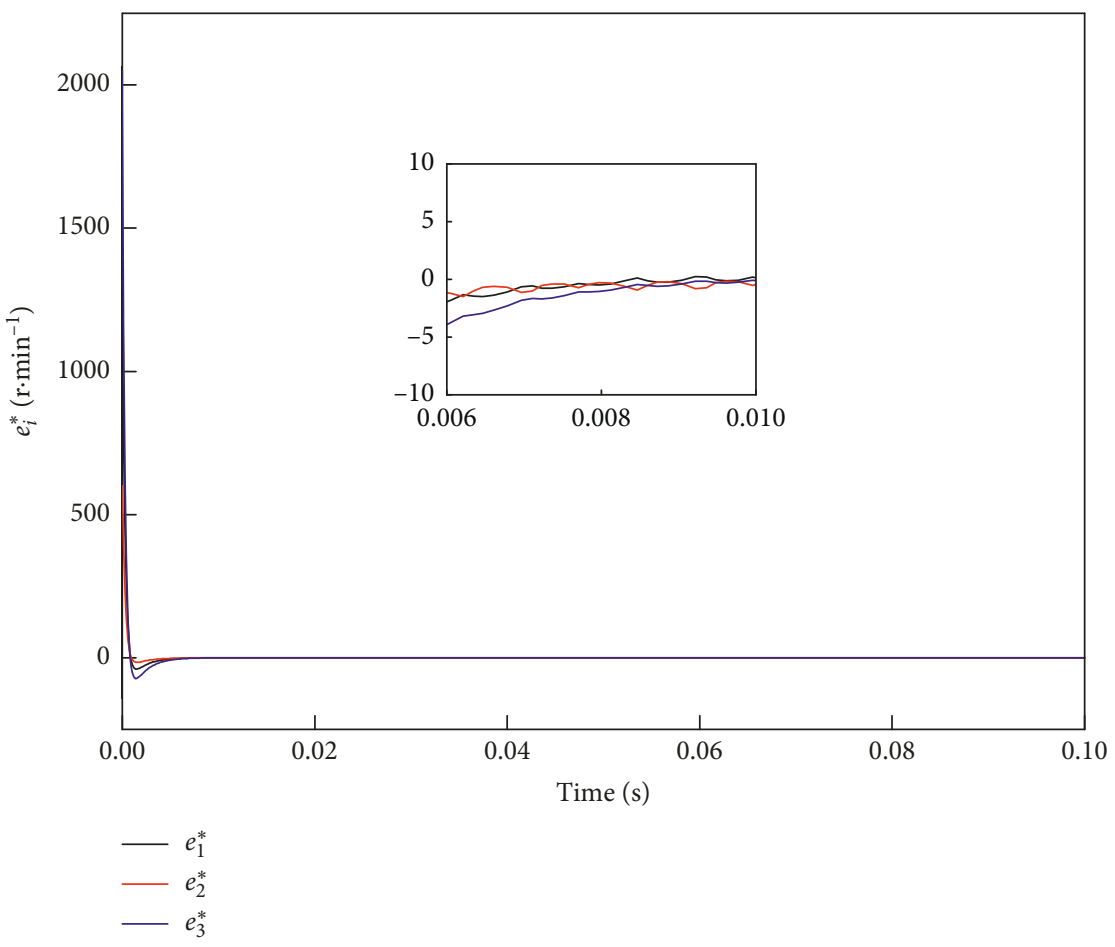

FIgURE 6: The velocity tracking error curves of all servos under the traditional PI control.

of all servos under the sliding mode variable control and traditional PI control are obtained, as shown in Figures 3 and 4 . The velocity tracking error curves of all servos are shown in Figures 5 and 6 . The synchronization error curves of all servos are shown in Figures 7 and 8. The error curves of the single axis system, as shown in Figures 9 and 10 .

Figures 3 and 4 show that under the sliding mode variable structure control and traditional PI control, the actual running velocity of each servo can follow the given speed of the 


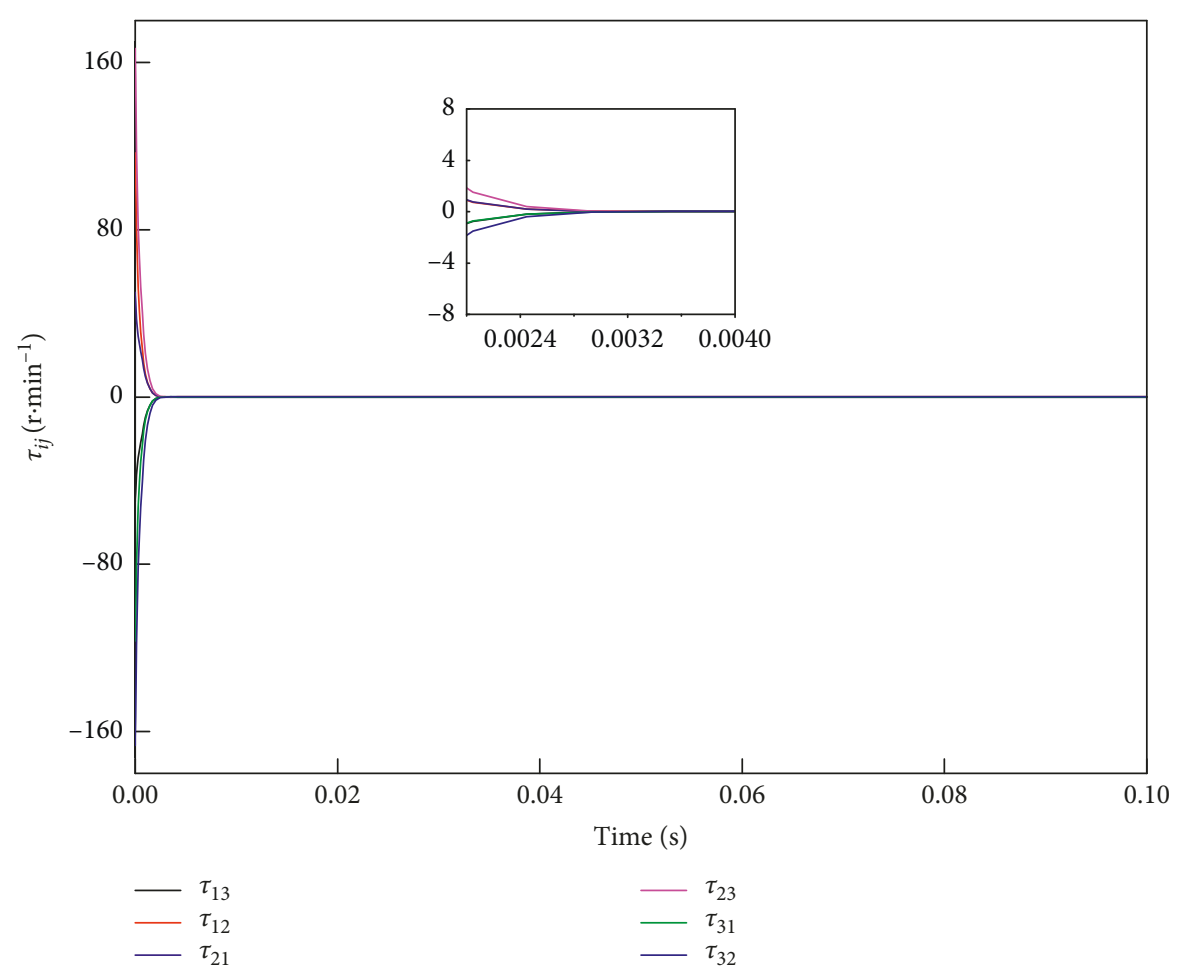

Figure 7: The synchronization error curves of all servos under the sliding mode variable control.

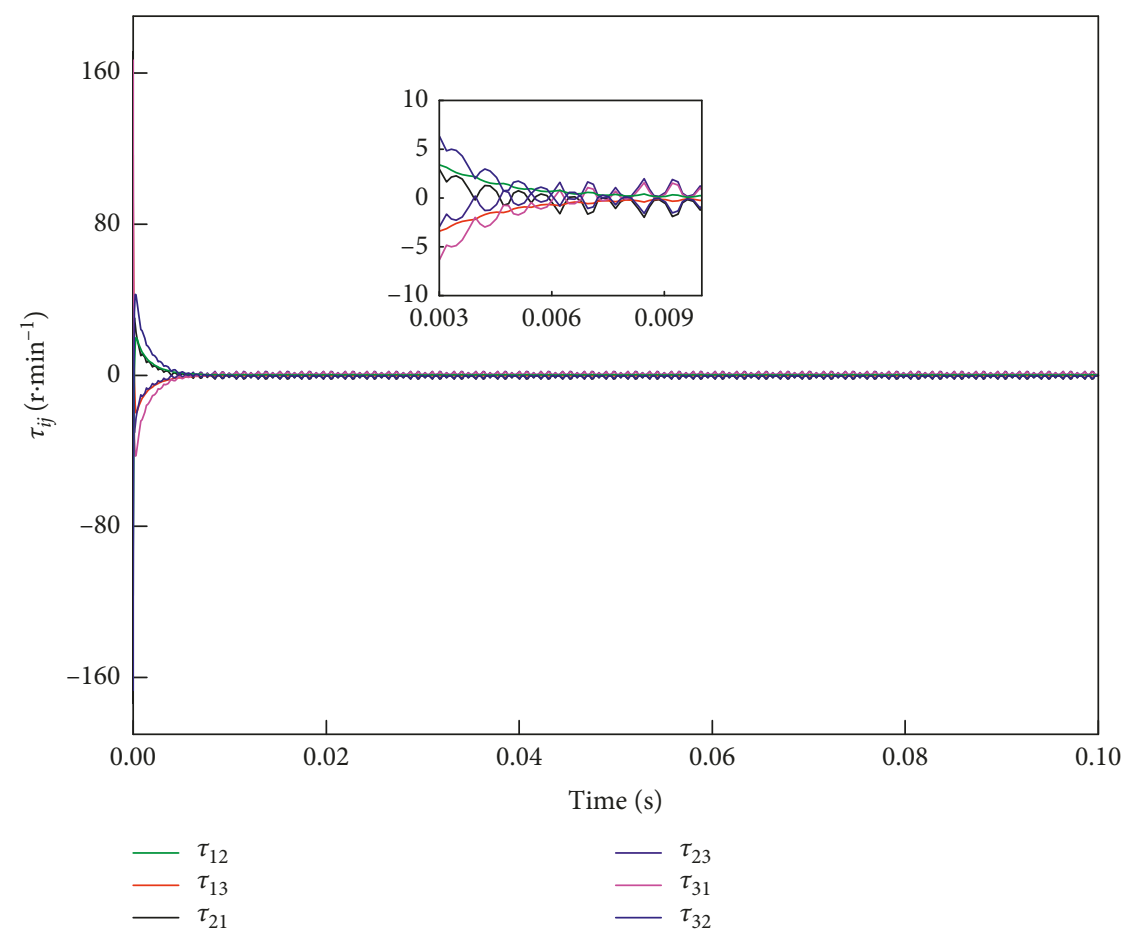

FIgURE 8: The synchronization error curves of all servos under the traditional PI control.

system rapidly. However, in terms of adjusting the time of the controller, only $0.0015 \mathrm{~s}$ is required for the sliding mode variable structure control, whereas $0.005 \mathrm{~s}$ is required for the traditional PI control. The velocity tracking using the sliding mode variable structure control is more rapid.
As shown in Figures 5 and 6, the two control methods evidently show differences in the velocity tracking errors of all servos. The error convergence time under the sliding mode variable structure control is approximately $0.002 \mathrm{~s}$, whereas the error convergence time under the traditional PI 


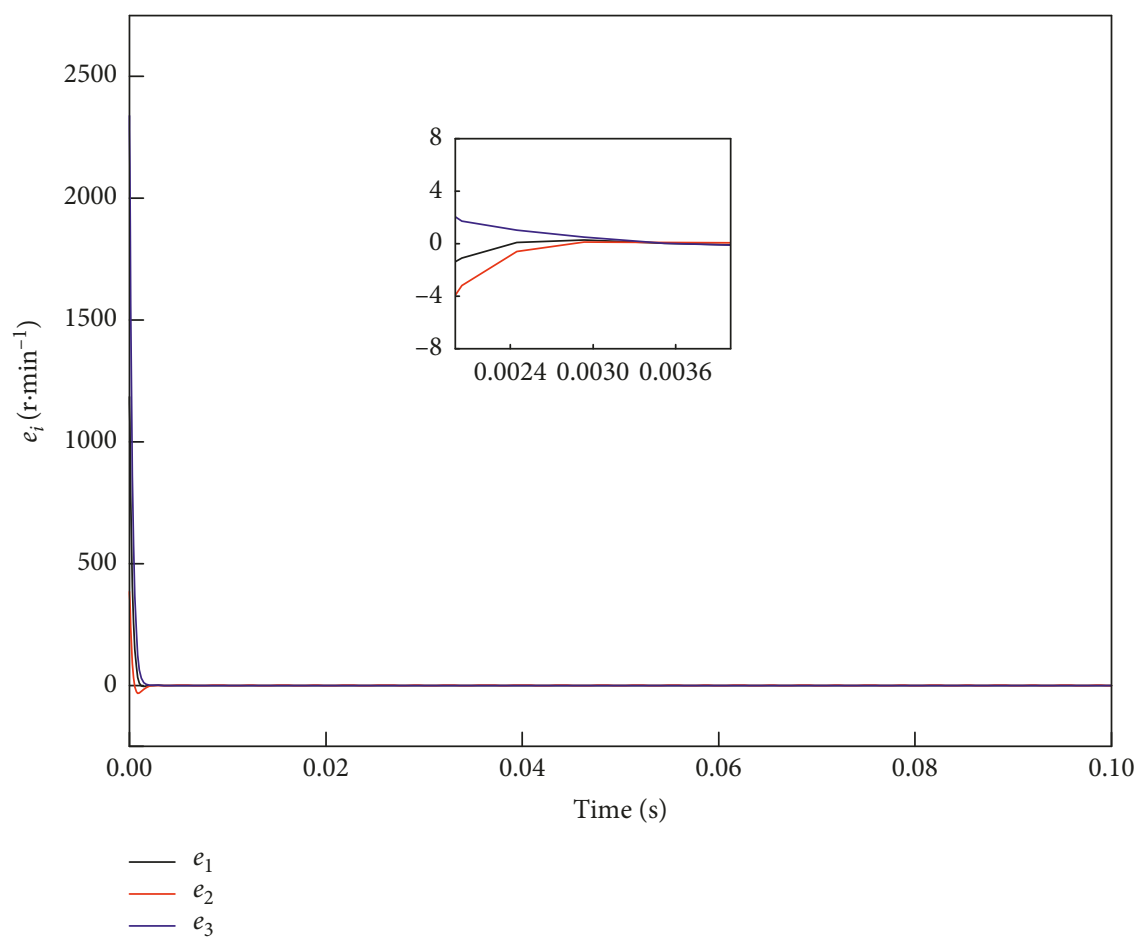

FIgure 9: The error curves of the single axis system under the sliding mode variable control.

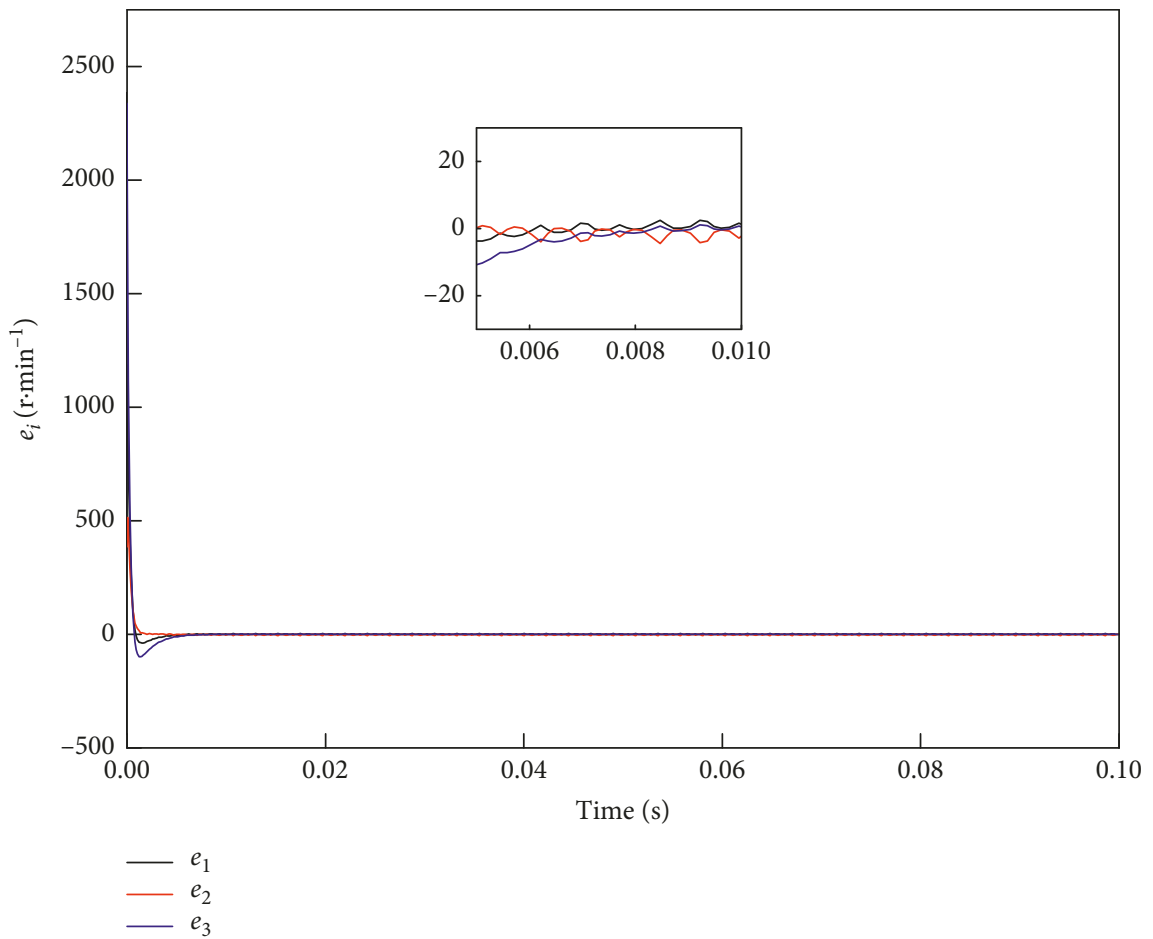

FIgURE 10: The error curves of the single axis system under the traditional PI control.

control is approximately $0.009 \mathrm{~s}$. The results indicate that the error convergence speed of the former is much faster than that of the latter.

Figures 7 and 8 show that the synchronization error convergence time among all servos under the sliding mode variable structure control is approximately $0.0025 \mathrm{~s}$. In addition, the convergence is stable and deviation-free. Moreover, the error convergence time under the traditional PI control is approximately $0.0065 \mathrm{~s}$. The error fluctuation is evident after the convergence is stable. This result shows that 

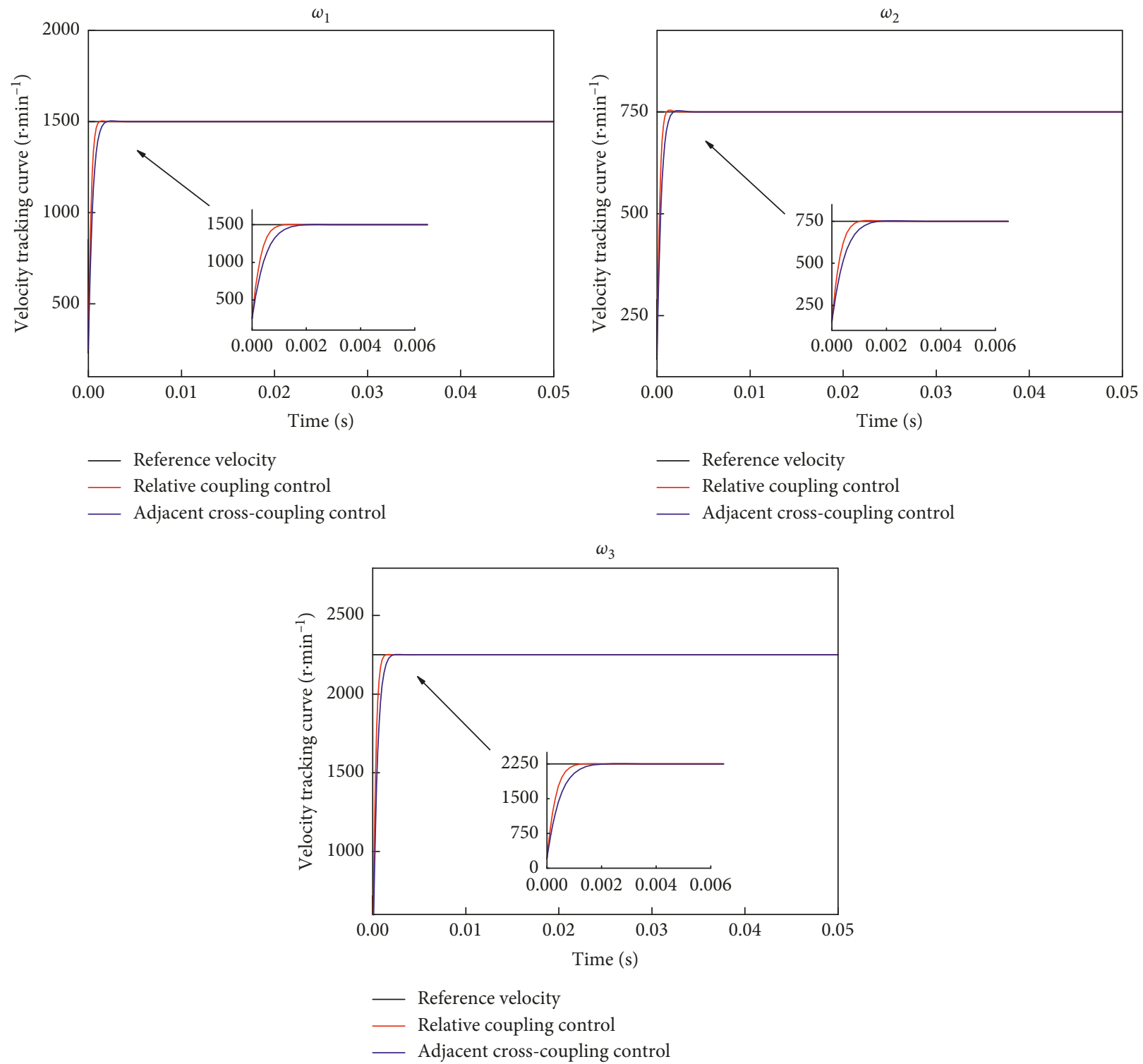

Figure 11: The velocity tracking curves of all servos under SMC.

the synchronization performance of all servos under SMC is better, and the error convergence stability is stronger.

Figures 9 and 10 present the sliding mode variable structure control shows excellent control performance in terms of error convergence of each single axis system. Evidently, the error convergence rate under SMC is faster and more stable than that under the traditional PI control.

Case 2. Under the same conditions, the simulation of the relative coupling control and adjacent cross-coupling control are compared and analysed.

Figure 11 illustrates the velocity tracking curves of the three servos with the relative coupling control and adjacent cross-coupling control in Case 2. It shows that the actual running velocity of each servo can rapidly follow the given speed of the system under relative coupling and the adjacent cross-coupling controls. However, the adjustment time under the relative coupling control is $0.001 \mathrm{~s}$ faster than that under the adjacent cross-coupling control.

Figure 12 illustrates the velocity-tracking error curves of the three servos with the relative coupling control and the adjacent cross-coupling control in Case 2. The performance comparisons of the two controls show that both of them have excellent control ability in terms of the velocitytracking error convergence of each servo, and the relative coupling control is better.

Figure 13 illustrates the synchronization error curves amongst the three servos with the relative coupling control and the adjacent cross-coupling control in Case 2. The result shows that the synchronization errors under the relative coupling control converge to zero faster than that under the adjacent cross-coupling control. However, the two structures show strong stability after the error convergence. 

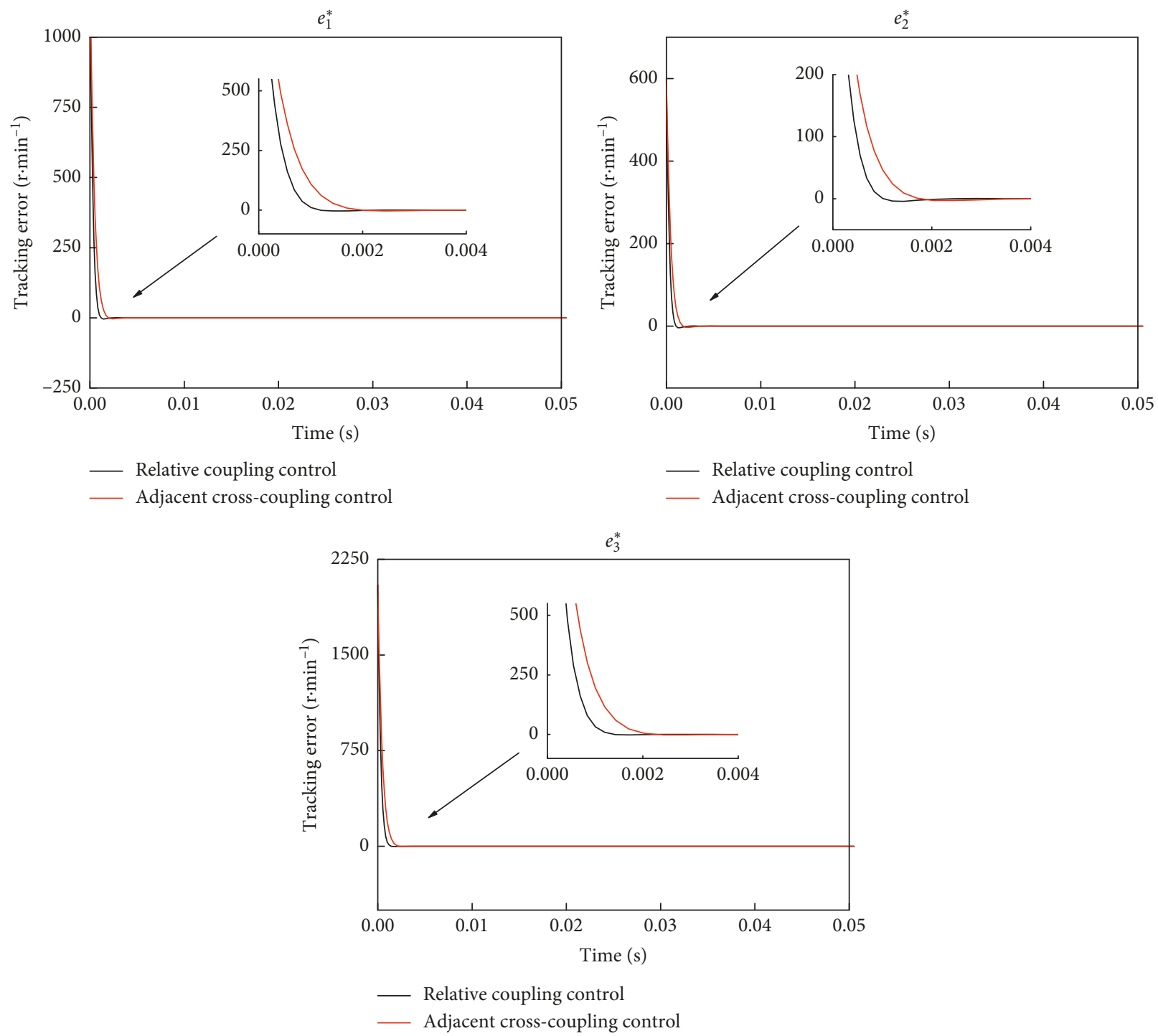

FIgURE 12: The velocity tracking error of all servos under SMC.

The simulation results of Cases 1 and 2 show that the relative coupling control strategy based on SMC is characterised by a rapid response and high accuracy in the multiaxis servo synergic control. These results indicate an excellent control performance, thereby further verifying the accuracy and effectiveness of the theory.

4.2. Multicycle Variable Proportion Simulation. The variable proportion simulation with $0.1 \mathrm{~s}$ as a cycle is performed based on the simulation mentioned in 4.1 to satisfy the actual requirements. The following five cycles are considered as examples for simulation verification. The system input of these five cycles and the proportion setting of axes are shown in Table 2.

Due to limited space, under the circumstance that servo parameters, load torques of all servos, and other experimental conditions are unchanged, only the simulation results of the variable input variable proportion system under the sliding mode variable structure control are provided, including the velocity tracking curves of all servos, as shown in Figure 14, the velocity tracking error curves of all servos, as shown in Figure 15, the synchronization error curves of all servos, as shown in Figure 16, and the system error curves, as shown in Figure 17.

Figure 14 shows that the velocity tracking is excellent in each cycle. In addition, no evident overshoot was found in the operation speed of each servo at the switching point of the system input and proportional change. Figure 15 shows that after the system input and the velocity proportions of all servos are changed, the velocity tracking error of all servos converges to zero rapidly and steadily. Figure 16 shows that the sudden change in the synchronization error caused by the changes in the system input and velocity proportions of all servos can rapidly converge to zero in a very short time. Thus, the system has excellent control performance for eliminating the synchronization errors of servos. Figure 17 shows that within five cycles, the error of each uniaxial 

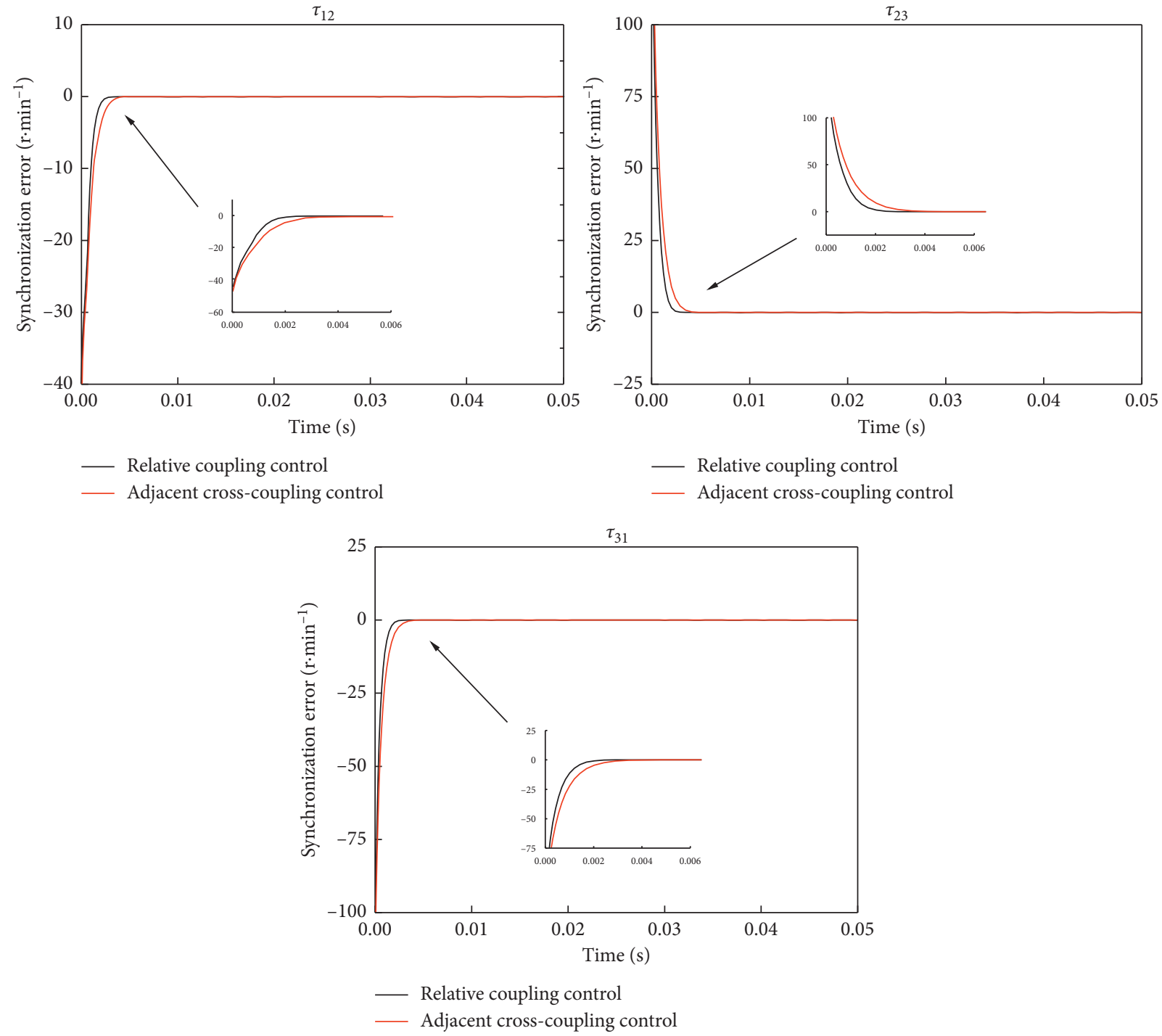

Figure 13: The synchronization error of all servos under SMC.

TABLE 2: System input and proportion setting.

\begin{tabular}{|c|c|c|c|c|}
\hline \multirow{2}{*}{ Cycle } & \multirow{2}{*}{ System input $\left(\omega_{1}^{*}\right)$} & \multicolumn{3}{|c|}{ Proportion setting } \\
\hline & & $K_{1}$ & $K_{2}$ & $K_{3}$ \\
\hline 1 & 1500 & 1 & 0.5 & 1.5 \\
\hline 2 & 2000 & 1 & 0.7 & 0.5 \\
\hline 3 & 800 & 1 & 1.5 & 2.5 \\
\hline 4 & 2200 & 1 & 0.4 & 0.7 \\
\hline 5 & 1300 & 1 & 1.4 & 0.5 \\
\hline
\end{tabular}

system can also converge stably and rapidly, and the convergence accuracy is high.

The simulation results show that the proposed method can be used to realize the multiaxis servo synergic control in variable proportion during the operation of the system.

\section{Physical Verification}

To further verify the feasibility of the proposed method, a physical model of the motion control platform of the dynamic seat is built to carry out the physical verification, as shown in Figure 18. The hardware used mainly includes the following: Mitsubishi 4/6 axis motion control module, Delta servo and driver, electric cylinder, and load seat. Among which, the rated power of the servo is $0.75 \mathrm{~kW}$, the rated speed is $3000 \mathrm{r} \cdot \mathrm{min}^{-1}$, the rated torque is $2.39 \mathrm{~N} \cdot \mathrm{m}$, and the load seat weight is $75 \mathrm{~kg}$.

Figure 19 shows that physical verification still takes five cycles as examples. Among them, (a), (c), and (e) represent the given velocity of each servo, and (b), (d), and (f) 


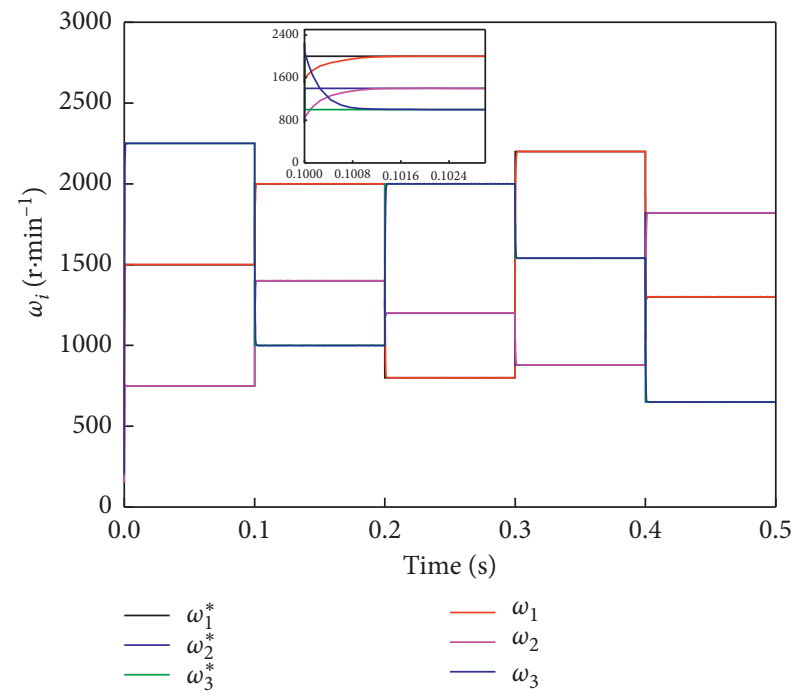

FIGURE 14: The velocity tracking curves of all servos under multiple cycles.

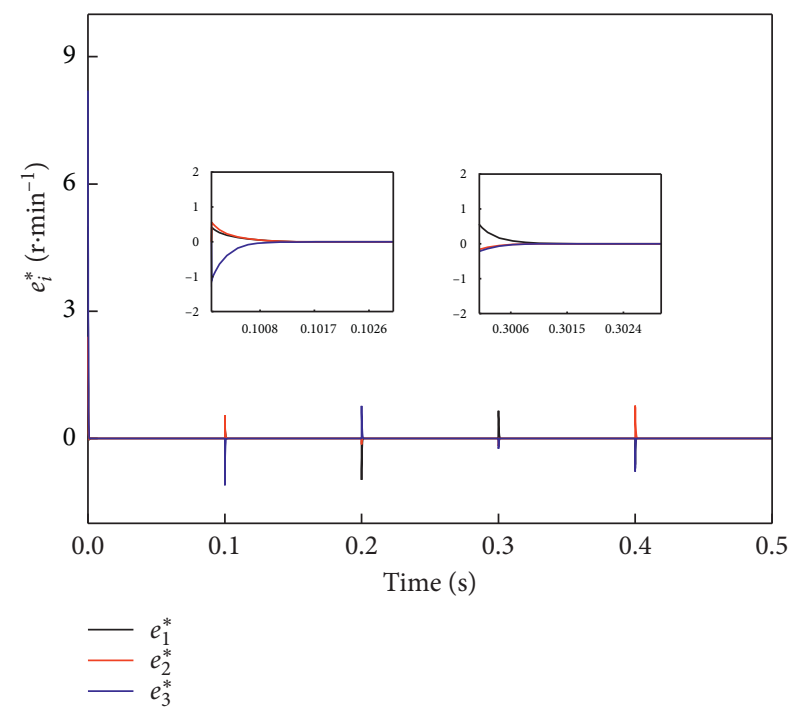

FIGURE 15: The velocity tracking error curves of all servos under multiple cycles.

represent the actual tracking velocity of each servo. In the figure, all servos can rapidly follow the target curve at the proportion switching point. The proposed method is accurate and feasible under the actual condition of variable input variable proportion, considering the uncertain disturbance in the actual environment.

\section{Conclusion}

A relative coupling control strategy based on the sliding mode controller is proposed to solve the synergic control problem of the multiaxis servo system under variable proportion conditions. The main conclusions are as follows: (1) a complete theoretical proof against the application of the proposed control strategy in the multiaxis

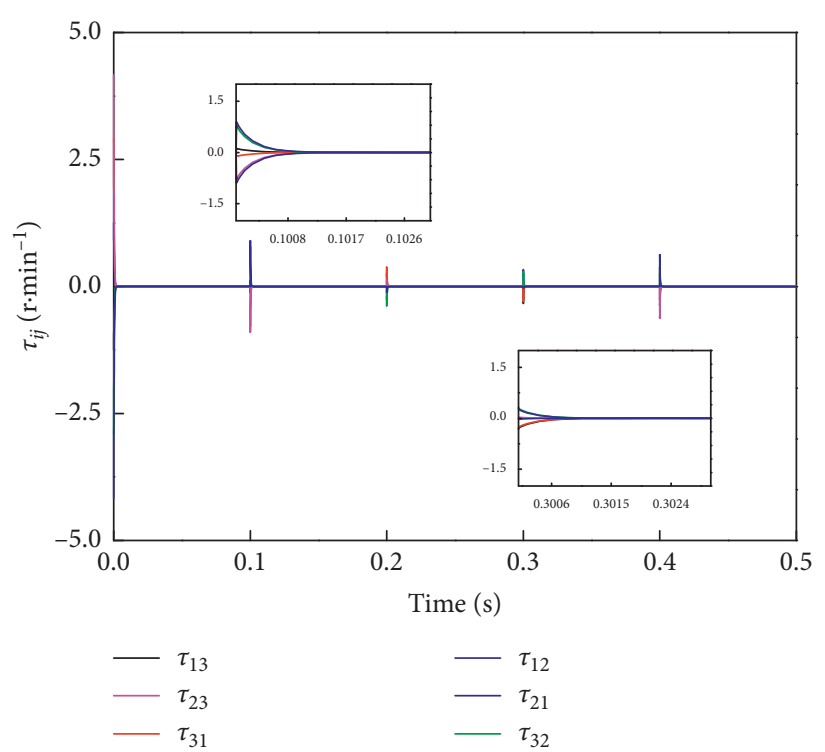

Figure 16: The synchronization error curves of all servos under multiple cycles.

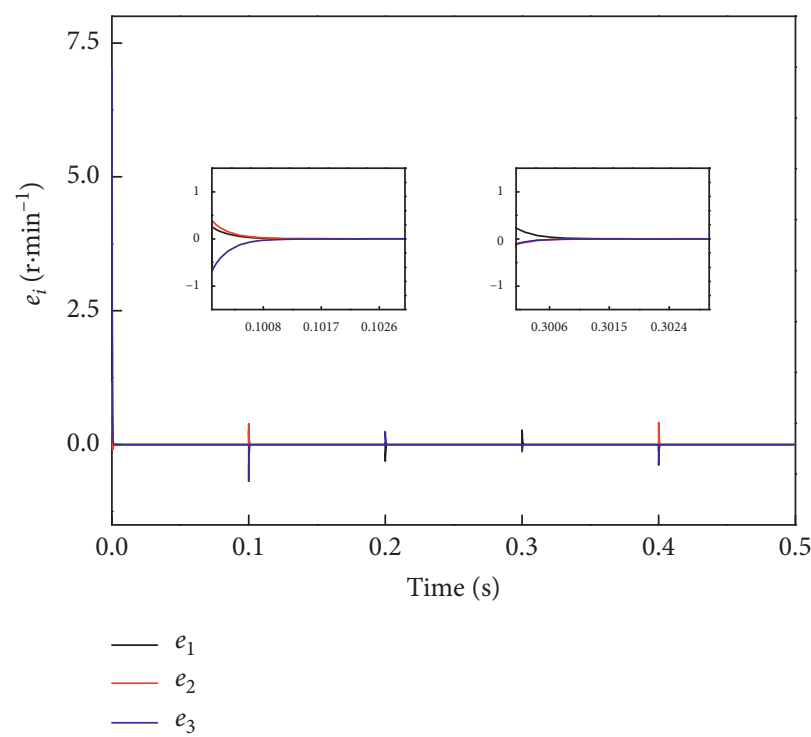

FIGURE 17: The system error curves under multiple cycles.

servo synergic control shows that the control strategy is effective and correct. (2) Compared with the simulation under the traditional PI control and the adjacent crosscoupling control based on the sliding mode controller, the relative coupling strategy based on the sliding mode variable structure control has excellent control performance in eliminating the tracking error of the servo during the system operation and the synchronization error among servos. Under variable proportion conditions, the method still has good synchronization and stability. (3) The physical verification by building a motion platform shows that the proposed method is feasible and has certain engineering application value. 


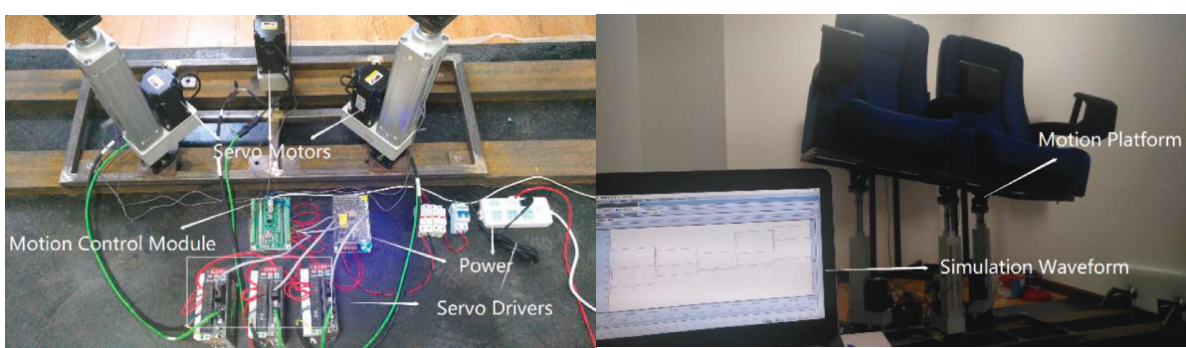

Figure 18: Physical model of the motion control platform of the dynamic seat.

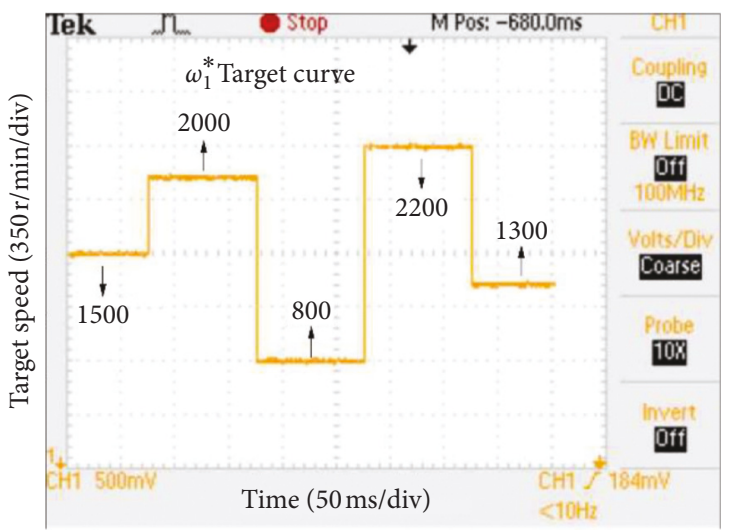

(a)

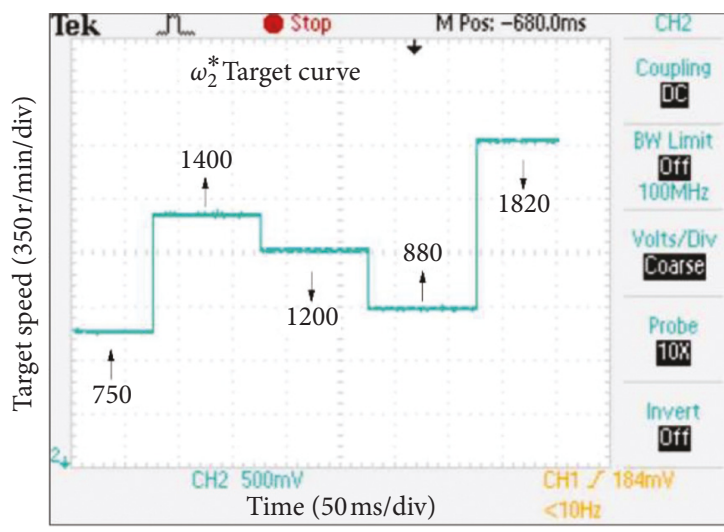

(c)

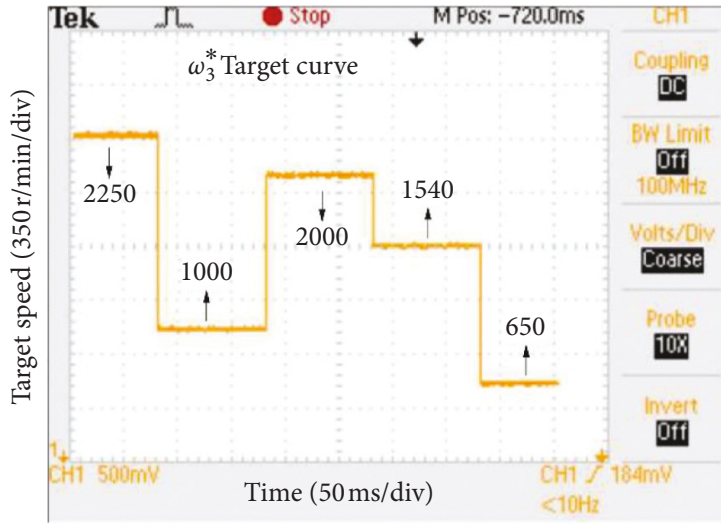

(e)

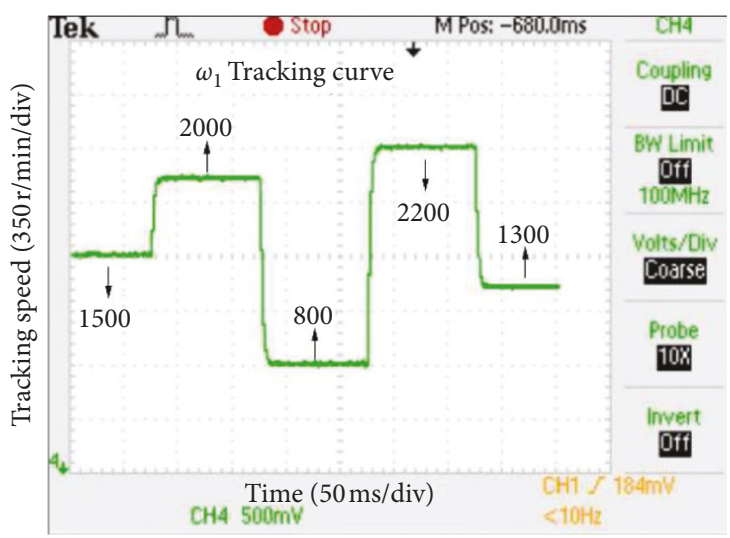

(b)

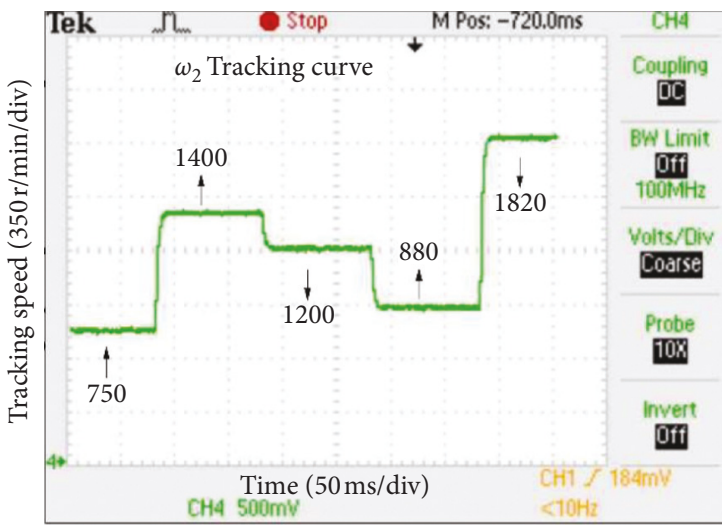

(d)

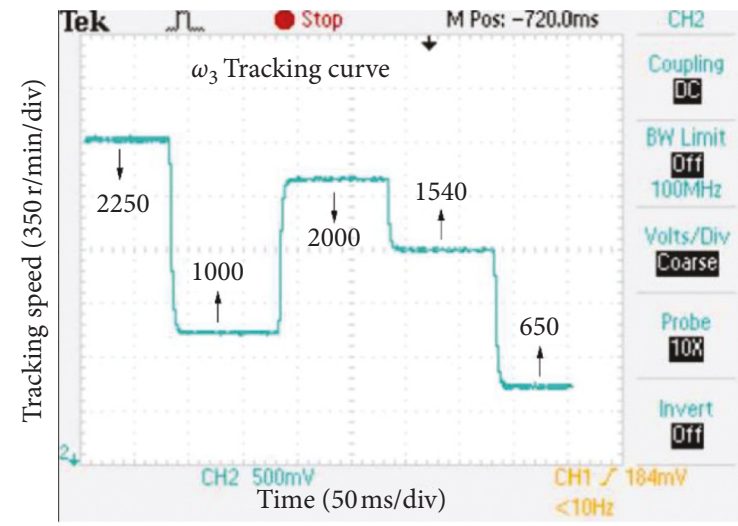

(f)

Figure 19: The velocity tracking curves of all servos. (a) The first servo's target speed. (b) The first servo's tracking speed. (c) The second servo's target speed. (d) The second servo's tracking speed. (e) The third servo's target speed. (f) The third servo's tracking speed. 


\section{Data Availability}

The data used to support the findings of this study are available from the corresponding author upon request.

\section{Conflicts of Interest}

The authors declare that they have no conflicts of interest.

\section{Acknowledgments}

This study was supported by the National Key R\&D Program of China (no. 2018YFD0400705), the Natural Science Foundation of China (nos. 61733004 and 61773159), and the Hunan Provincial Natural Science Foundation of China (nos. 2017JJ4031 and 2018JJ4066).

\section{References}

[1] S. Hu, X. Ren, and Z. Wei, "Synchronous control of multimotor driving servo systems," in Proceedings of the Chinese Intelligent Systems Conference, pp. 611-620, MudanJiang, China, September 2017.

[2] F. He and C. Wang, "Cross-coupling synchronous control of dual-motor networked motion control system," in Proceedings of the 36th Chinese Control Conference, Dalian, China, July 2017.

[3] C. H. Vismay and P. V. P. Patel, "Multi-motor synchronization techniques," International Journal of Science, Engineering and Technology Research (IJSETR), vol. 3, no. 2, pp. 319-322, 2014.

[4] M. Kiyoshi and T. Motai, "Synchronization of two motion control axes under adaptive feedforward control," Adaptive \& Learning Control, vol. 114, no. 2, pp. 196-203, 1992.

[5] S. Lin, Y. Cai, B. Yang, and W. Zhang, "Electrical line-shafting control for motor speed synchronization using sliding mode controller and disturbance observer," IET Control Theory \& Applications, vol. 11, no. 2, pp. 205-212, 2016.

[6] C.-S. Chen and L.-Y. Chen, "Robust cross-coupling synchronous control by shaping position commands in multiaxes system," IEEE Transactions on Industrial Electronics, vol. 59, no. 12, pp. 4761-4773, 2012.

[7] J. Li, Y. Fang, and X. Huang, "Comparison of synchronization control techniques for traction motors of high-speed trains," in Proceedings of the International Conference on Electrical Machines \& Systems, pp. 2114-2119, Hangzhou, China, October 2014.

[8] F. J. Perez-Pinal, G. Calderon, and I. Araujo-Vargas, "Relative coupling strategy," in Proceedings of the IEEE International Electric Machines and Drives Conference, vol. 2, no. 3, pp. 1162-1166, Madison, WI, USA, June 2003.

[9] T. Shi, X. Xin, and C. Xia, "Multi-motor speed synchronous control based on improved relative coupling structure with a virtual motor," Proceedings of the CSEE, vol. 37, no. 23, pp. 7004-7013, 2017.

[10] T. Shi, H. Liu, Q. Geng, and C. Xia, "An improved relative coupling control structure for multi-motor speed synchronous driving system," IET Electric Power Applications, vol. 10, no. 6, pp. 451-457, 2016.

[11] X. Peng, W. Liu, and Q. Zhang, "Synchronized control of multi-motor based on the improved Relative Coupling Control," Journal of Hunan University, vol. 40, no. 11, pp. 77-83, 2013.
[12] L.-B. Li, L.-L. Sun, S.-Z. Zhang, and Q.-Q. Yang, "Speed tracking and synchronization of multiple motors using ring coupling control and adaptive sliding mode control," ISA Transactions, vol. 58, pp. 635-649, 2015.

[13] R. Liu, J. Sun, Y. Luo, and W. Sun, "Research on multi-motor sliding-mode synchronization control based on ring coupling strategy," China Mechanical Engineering, vol. 21, no. 22, pp. 2662-2665, 2010.

[14] P. Zhang, J. Zhang, D. He, and B. Zhang, "Based on adjacent cross-coupling of multi-motor synchronous drive," Advanced Materials Research, vol. 201-203, pp. 1093-1097, 2011.

[15] L. Li, L. Sun, and S. Zhang, "Mean deviation coupling synchronous control for multiple motors via second-order adaptive sliding mode control," ISA Transactions, vol. 62, pp. 222-235, 2016.

[16] B. Zhao, F. Gao, and T. Lei, "Normalized coupling method for speed synchronization of multi-axis driving vehicles," International Journal of Advanced Robotic Systems, vol. 9, no. 2, p. $50,2012$.

[17] H. H. Shi, X. Wu, L. Hua, and H. G. Ji, "The simulation research of synchronization control based on the virtual shaft control and the relative coupling control," Advanced Materials Research, vol. 1049-1050, pp. 1111-1115, 2014.

[18] W. Zhao and X. Ren, "Neural network-based tracking and synchronization control for nonlinear multi-motor driving servomechanism," in Proceedings of the IEEE 2016 35th Chinese Control Conference (CCC), Chengdu, China, July 2016.

[19] W. Huang, X. Chi, and Y. Sun, "Research on relative coupling control for multi-servomotor synchronized control based on wavelet neural network," Automation \& Instrumentation, vol. 11, pp. 57-61, 2016.

[20] Z. Huang, Y. Li, G. Song, X. Zhang, and Z. Zhang, "Speed and phase adjacent cross-coupling synchronous control of multiexciters in vibration system considering material influence," IEEE Access, vol. 7, pp. 63204-63216, 2019.

[21] W. Chen, Y. Wu, R. Du, Q. Chen, and X. Wu, "Speed tracking and synchronization of a dual-motor system via second order sliding mode control," Mathematical Problems in Engineering, vol. 2013, Article ID 919837, 10 pages, 2013.

[22] C. Sun, G. Gong, H. Yang, and F. Wang, "Fuzzy sliding mode control for synchronization of multiple induction motors drive," Transactions of the Institute of Measurement and Control, vol. 41, no. 11, pp. 3223-3234, 2019.

[23] W. Gao, X. Chen, H. Du, and S. Bai, "Position tracking control for permanent magnet linear motor via continuous-time fast terminal sliding mode control," Journal of Control Science and Engineering, vol. 2018, Article ID 3813624, 6 pages, 2018.

[24] Q. Jiang, M. Liao, and M. Luo, "Design of permanent magnet synchronous motor speed loop controller based on sliding mode control algorithm," in Proceedings of the Materials Science \& Engineering Conference Series, Istanbul, Turkey, August 2018.

[25] L. Cao, W. Wei, C.-W. Li, and Y. Hua, "Synchronization control in crane lifter based on relative coupling strategy," Computer Engineering \& Applications, vol. 44, no. 25, pp. 233-235, 2008.

[26] Y.-H. Lan and L. Lei-Zhou, "Backstepping control with disturbance observer for permanent magnet synchronous motor," Journal of Control Science and Engineering, vol. 2018, Article ID 4938389, 8 pages, 2018.

[27] S. Oussama, K. Amor, A. Moez et al., "A sliding-mode observer for high-performance sensorless control of PMSM with 
initial rotor position detection," International Journal of Control, vol. 90, no. 2, pp. 377-392, 2017.

[28] L. Li, J. Hui, L. Zhang, and H. Sun, "Study on torque ripple attenuation for BLDCM based on vector control method," in Proceedings of the Second International Conference on Intelligent Networks \& Intelligent Systems, Tianjin, China, November 2009.

[29] J.-W. Jung, V. Q. Leu, T. D. Do, E.-K. Kim, and H. H. Choi, "Adaptive PID speed control design for permanent magnet synchronous motor drives," IEEE Transactions on Power Electronics, vol. 30, no. 2, pp. 900-908, 2015.

[30] J. He, L. Mi, J. Liu, X. Cheng, Z. Lin, and C. Zhang, "Ring coupling-based collaborative fault-tolerant control for multirobot actuator fault," International Journal of Robotics and Automation, vol. 33, no. 6, pp. 672-680, 2018. 


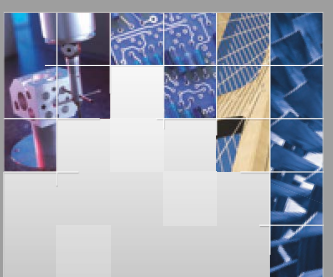

\section{Enfincering}
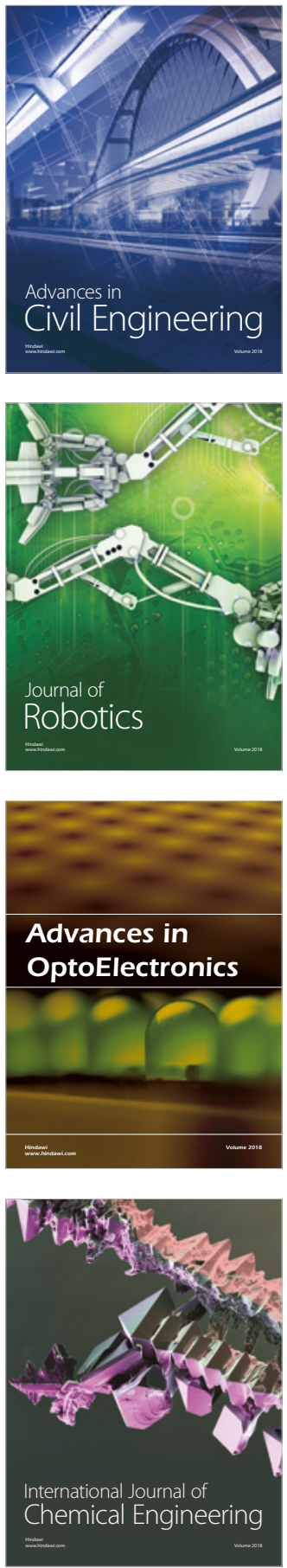

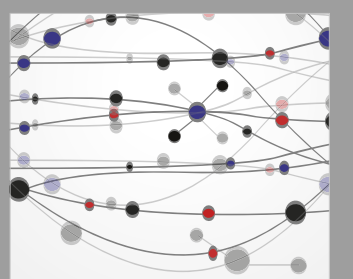

\section{Rotating \\ Machinery}

The Scientific World Journal

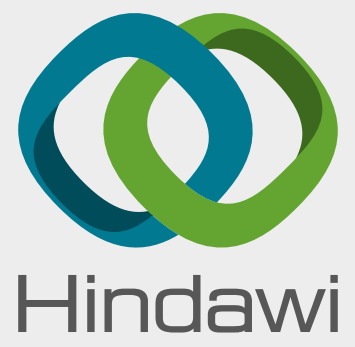

Submit your manuscripts at

www.hindawi.com
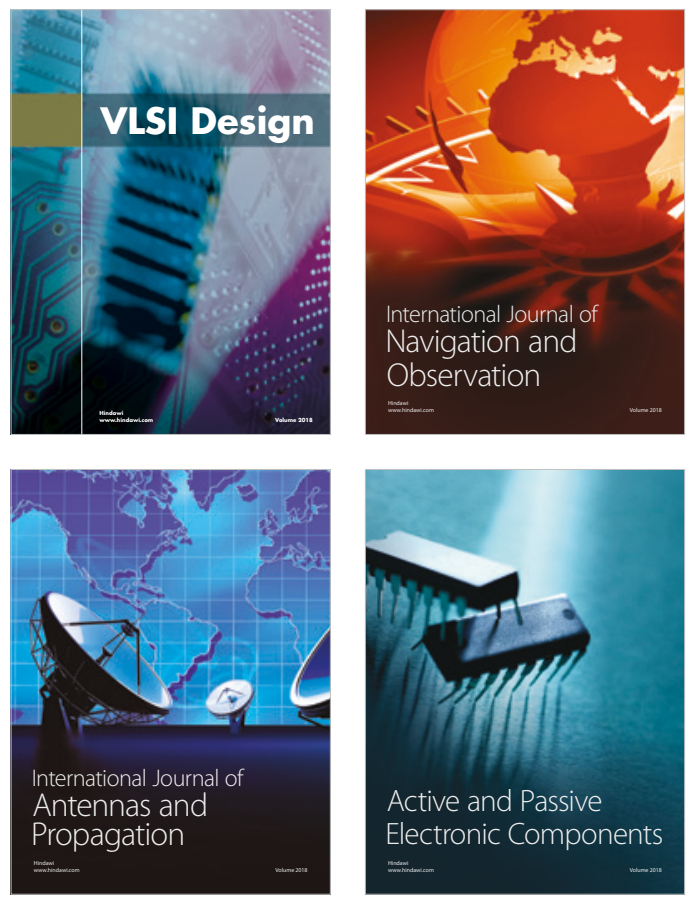
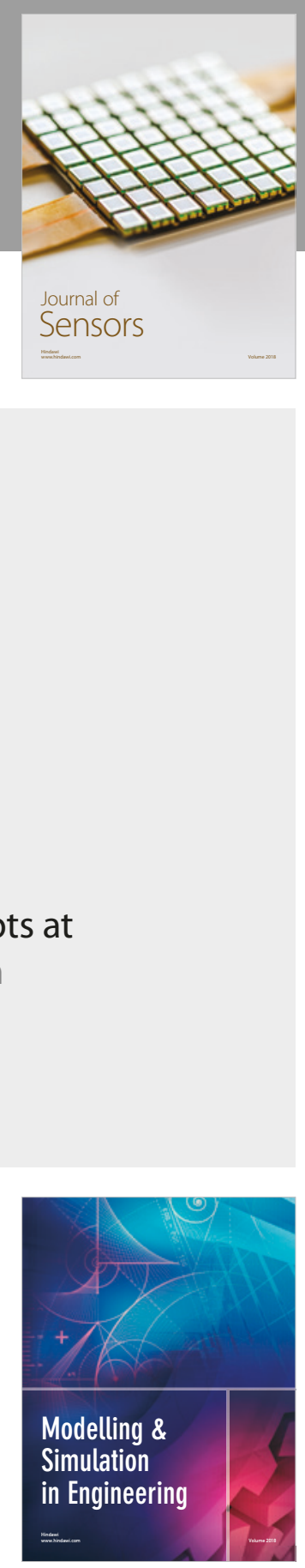

\section{Advances \\ Multimedia}
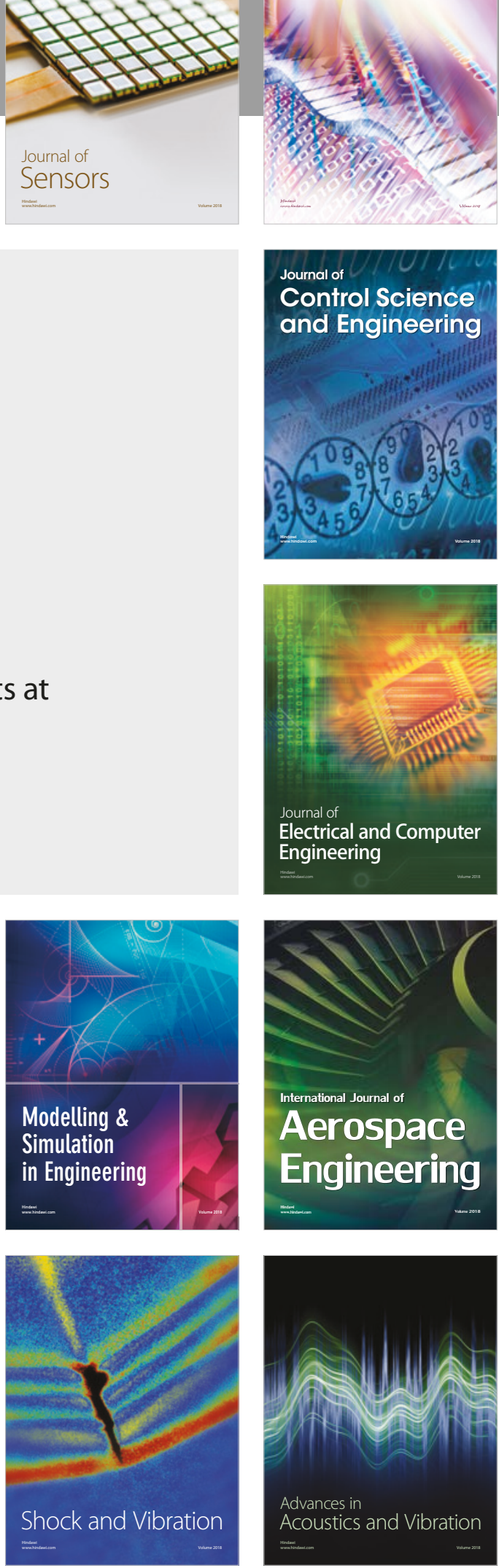